\title{
A Educação Ambiental Revelada no (Re)Trato dos Espaços Urbanos Vazios: Desafios das Vigilâncias Ambiental e Epidemiológica
}

\section{The Environmental Education Revealed in the (Re) Treatment of Empty Urban Spaces: Challenges of Environmental and Epidemiological Surveillance}

\section{Educación Ambiental Revelada en (Re) Tratamiento de Espacios Urbanos Vacíos: Desafíos de la Vigilancia Ambiental y Epidemiológica}

\author{
Flávia Nunes Ferreira de Araújo ${ }^{1}$ \\ Maria de Fátima Nóbrega Barbosa ${ }^{2}$
}

\begin{abstract}
Resumo
O objetivo do estudo foi compreender o processo da educação ambiental revelada no (re)trato dos espaços urbanos vazios e desafios das Vigilâncias Ambiental e Epidemiológica. Trata-se de uma pesquisa de campo, realizada por entrevista com a coordenação das Vigilâncias Ambiental e Epidemiológica de Campina Grande - Paraíba, além de registros fotográficos para mostrar a exposição de resíduos sólidos em espaços vazios. Para a Vigilância Epidemiológica, os indicadores sociais, econômicos e ambientais que mais prejudicam e desafiam a efetividade das ações coincidem com os problemas da Vigilância Ambiental: baixa escolaridade do chefe da família; educação ambiental inconsistente; terrenos baldios sem os devidos cuidados de seus responsáveis e, ainda, doenças provocadas por insetos e roedores. As imagens registradas revelam a necessidade de trabalhar a educação ambiental com base em uma nova práxis, possibilitando um meio ambiente mais sustentável para gerações presentes e futuras.
\end{abstract}

Palavras-Chave: Educação Ambiental. Sustentabilidade. Comportamentos ecológicos. Resíduos Sólidos. Espaços Urbanos.

\begin{abstract}
The objective of the study was to understand the process of environmental education revealed in the (re) treatment of empty urban spaces and challenges of Environmental and Epidemiological Surveillance. This is a field survey, conducted by interview with the Environmental and Epidemiological Surveillance of Campina Grande - Paraíba, as well as photographic records to show the exposure of solid waste in empty spaces. For Epidemiological Surveillance, the social, economic and environmental indicators that most damage and challenge the effectiveness of actions coincide with the problems of Environmental Surveillance: low level of education of the head of the family; inconsistent environmental education; wastelands without the proper care of their caretakers, and diseases caused by insects and rodents. The recorded images reveal the need to work on environmental education based on a new praxis, enabling a more sustainable environment for present and future generations.
\end{abstract}

Keywords: Environmental Education. Sustainability. Ecological behaviors. Solid waste. Urban Spaces.

\section{Resumen}

El objetivo del estudio fue comprender el proceso de educación ambiental revelado en el (re) tratamiento de espacios urbanos vacíos y los desafíos de las Vigilancias Ambiental y Epidemiológica. Este es un estudio de campo, realizado mediante una entrevista con la Vigilancia Ambiental y Epidemiológica de Campina Grande Paraíba, así como registros fotográficos para mostrar la exposición de desechos sólidos en espacios vacíos. Para la Vigilancia Epidemiológica, los indicadores sociales, económicos y ambientales que más dañan y desafían la efectividad de las acciones coinciden con los problemas de la Vigilancia Ambiental: bajo nivel de educación del

\footnotetext{
${ }^{1}$ Doutoranda em Recursos Naturais - Universidade Federal de Campina Grande.

E-mail: flaviapsfcg@hotmail.com

${ }^{2}$ Doutora em Recursos Naturais - Professora Adjunta do Programa de Pós-graduação em Recursos Naturais da

Universidade Federal de Campina Grande.

E-mail: nfnobregabarbosa@gmail.com
} 
jefe de familia; educación ambiental inconsistente; Tierras baldías sin el cuidado adecuado de sus cuidadores, y enfermedades causadas por insectos y roedores. Las imágenes grabadas revelan la necesidad de trabajar en la educación ambiental basada en una nueva práctica, lo que permite un entorno más sostenible para las generaciones presentes y futuras.

Palabras clave: Educación ambiental. Sostenibilidad. Comportamiento ecológico. Residuos sólidos. Espacios urbanos.

\section{Introdução}

As sociedades modernas têm estimulado novos padrões de consumo a partir da lógica capitalista, gerando grandes excedentes de resíduos sólidos, que acabam por provocar impactos ambientais, ocasionados pela disposição inadequada desses resíduos sólidos no meio ambiente, trazendo implicações à saúde pública e significantes problemas ambientais nos espaços urbanos (MORAES et al., 2017).

A peculiaridade das culturas dos antepassados, até meados do século XX, em relação aos resíduos produzidos pelo homem era de livrar-se rapidamente das sobras que não possuíam mais utilidade, as quais eram lançadas e dispostas a céu aberto, em ravinas, despenhadeiros ou beira de rios. A maneira de viver em que o indivíduo não é participante do território e não mantém relação de pertencimento aos artefatos que conquista torna seus resíduos como coisas efêmeras, espontaneamente descartáveis, de valor insignificante e residual. Dessa forma, os resíduos sólidos gerados e sua destinação ou disposição resultam de uma relação estabelecida pela sociedade com o ambiente, da ação humana no espaço e sua territorialidade (GUADAGNIN; SELAU; CADORIN, 2018).

O comprometimento da preservação do meio ambiente, no contexto geral, provavelmente esteja relacionado ao comportamento ecológico. Para Franco (2012), comportamento ecológico indica um conjunto de condutas responsáveis em relação ao meio ambiente, por parte do indivíduo, as quais estão associadas ao não desperdício de recursos naturais, respeito aos limites do meio ambiente, consumo racional e preocupação em termos de sustentabilidade. O comportamento ecológico é central quando se discute meio ambiente, porque são ações humanas que, direta e indiretamente, contribuem para a degradação ambiental acelerada e provocam conflitos de ordem socioambiental de difícil resolução no curto prazo.

Os principais geradores de resíduos no espaço urbano são os domicílios, entulhos da construção civil, galhadas e restos de podas de árvores, que são dispostos de modo inadequado, permanecendo, por longo período, sem a coleta adequada, causando significativos impactos às condições estéticas e sanitárias do meio ambiente, afetando a segurança, o bem-estar dos habitantes e agravando os riscos à saúde pública, pois esses ambientes favorecem a proliferação de insetos e roedores que são vetores de inúmeras doenças (TESSARO; SÁ; SCREMIN, 2012).

É importante considerar que a formação de espaços urbanos vazios, também conhecidos como terrenos baldios, deriva de um processo complexo. O crescimento das cidades nas últimas décadas levou à necessidade de novos empreendimentos, geralmente afastados dos grandes aglomerados, gerando, assim, vazios urbanos (terrenos vagos, subaproveitados, terras devolutas), ou o parcelamento do espaço urbano. Nesse parcelamento, serviços básicos não são, na maioria das vezes, fornecidos. Com o processo de vazio nas áreas urbanas, em que a especulação imobiliária é desvalorizada, esses terrenos ficam por longos períodos desabitados, assim, a população vem e deposita os resíduos sólidos nesses terrenos inutilizados (SILVA et al., 2010).

Para Philippi Júnior e Aguiar (2005), o mau hábito de depositar resíduos em terrenos baldios está inserido no contexto de falha na educação ambiental (EA), tida como um ramo da 
educação cujo objetivo é disseminar o conhecimento sobre o meio ambiente, na busca da preservação e utilização sustentável dos recursos naturais.

A EA com ênfase na interdisciplinaridade é importante porque proporciona uma melhor leitura da realidade e promove uma postura crítica do cidadão frente aos problemas socioambientais. Nessa perspectiva, Soares, Carpilovsky e Costabeber (2012) assinalam que é preciso fazer uma reflexão aprofundada à medida que a saúde e a qualidade de vida dessa geração, e das futuras, demandam um desenvolvimento sustentável.

A complexidade dos determinantes sociais e ambientais e sua cadeia de efeitos revelam que os fatores de ordem ambiental contribuem fortemente para os quadros globais de morbimortalidade, estimando que $24 \%$ da carga total de doenças e $23 \%$ de todos os óbitos podem ser fortemente atribuíveis a fatores ambientais (PRÜSS-ÜSTÜN; CORVALÁN, 2006). Esta carga ambiental de doenças se expressa como um desafio para a Vigilância Epidemiológica, pois além da contaminação, o problema dos resíduos em espaços urbanos vazios vincula-se ao longo tempo de permanência no ambiente, porque seu processo de degradação produz gases que têm fortes odores e atraem baratas, moscas, ratos e escorpiões.

Souza e Souza (2013) relatam que insetos e roedores podem ser vetores mecânicos de agentes etiológicos causadores de doenças, tais como: diarreias infecciosas, amebíase, giardíase, salmonelose, helmintoses, dentre outras. Esses vetores não ficam somente no resíduo, deslocam-se até as habitações mais próximas, trazendo uma série de consequências à saúde pública. A Vigilância Epidemiológica é definida pela Lei n 8.080/90 como:

Um conjunto de ações que proporciona o conhecimento, a detecção ou prevenção de qualquer mudança nos fatores determinantes e condicionantes de saúde individual ou coletiva, com a finalidade de recomendar e adotar as medidas de prevenção e controle das doenças ou agravos (BRASIL, 2009).

Dessa forma, este trabalho foi desenvolvido acreditando-se na contribuição para um melhor conhecimento das pressões exercidas pela ação antrópica causada ao meio ambiente, do estado em que se encontra esse meio ambiente, dos impactos provocados, bem como das respostas que a sociedade e o poder público têm proposto, oportunizando a verificação do interrelacionamento das atividades antrópicas e seus indispensáveis reflexos no meio ambiente.

Assim, o objetivo do estudo foi compreender o processo da educação ambiental revelada no (re)trato dos espaços urbanos vazios e os desafios das Vigilâncias Ambiental e Epidemiológica em uma perspectiva de transformar a relação entre a sociedade e meio ambiente.

\section{Revisão Teórica}

A compreensão ambiental envolve uma visão dialética, sistêmica e complexa, exigindo ainda um encontro das abordagens inter e transdisciplinar. A assimilação e dispersão da compreensão das relações entre natureza e sociedade são extremamente favorecidas por meio da EA e de sua práxis. Assim, do ponto de vista pedagógico e aplicado, a EA objetiva contribuir na formação do comportamento individual e coletivo, de maneira que a população se habilite a participar dos processos de planejamento e gestão ambiental (SEABRA, 2013).

Para uma melhor explanação dessa conjectura, esta seção da Revisão Teórica subdividese em dois subtópicos, os quais exploram os principais constructos teóricos necessários às reflexões posteriores, sendo o primeiro uma compreensão da educação ambiental e, o segundo, espaços urbanos vazios com resíduos sólidos.

\subsection{Uma compreensão da educação ambiental}


A preocupação com o desenvolvimento sustentável representa a possibilidade de garantir mudanças sociopolíticas que não comprometam os sistemas ecológicos e sociais que sustentam as comunidades. A complexidade desse processo de transformação de um planeta, não apenas crescentemente ameaçado, mas também diretamente afetado pelos riscos socioambientais e seus danos, é cada vez mais notória. Para Beck (2009) a concepção sociedade de risco, amplia a compreensão de um cenário marcado por nova lógica de distribuição dos riscos e, certamente, esses riscos trazem irrecuperáveis comprometimentos à saúde do Planeta, daí a urgente necessidade de se compreender a EA e suas possíveis contribuições, além de verificar onde há falhas.

Existem várias concepções, nos termos legais, sobre o que consiste a EA (BRASIL, 1999; BRASIL, 2012), embora, em sua maioria, haja uma visão comum de que consiste em um processo de aprendizagem e comunicação na abordagem das questões relacionadas às interações entre os seres humanos e o seu meio. Pode enfocar diferentes níveis de abrangência e escalas dimensionais, perpassando pelos âmbitos global, nacional, regional, estadual, municipal e local.

De acordo com a Lei Federal 9.795, de 27 de abril de 1999, a EA compreende:

Os processos por meio dos quais o indivíduo e a coletividade constroem valores sociais, conhecimentos, habilidades, atitudes e competências voltadas para a conservação do meio ambiente, bem de uso comum do povo, essencial à sadia qualidade de vida e sua sustentabilidade (BRASIL, 1999, p.1).

As Diretrizes Curriculares Nacionais para a Educação Ambiental, Art. $2^{\circ}$ (2012, p. 2) definem EA como:

Uma dimensão da educação, atividade intencional da prática social, que deve imprimir ao desenvolvimento individual um caráter social em sua relação com a natureza e com os outros seres humanos, visando potencializar essa atividade humana com a finalidade de torná-la plena de prática social e de ética ambiental (BRASIL, 2012, p.2).

A Política Nacional de Educação Ambiental descreve que a EA deve proporcionar as condições para o desenvolvimento das capacidades necessárias para que grupos sociais, em diferentes contextos socioambientais do país, intervenham de modo qualificado na gestão do uso dos recursos ambientais e na concepção e aplicação de decisões que afetem a qualidade do ambiente, tanto físico-natural quanto construído, ou seja, a EA como instrumento de participação e controle social na gestão ambiental pública (BRASIL, 1999).

Com uma nova metodologia sustentada na Teoria da Complexidade, defendida por Morin (2015), é possível ampliar o nível de percepção e conhecimentos relacionados às interrelações socioambientais no contexto atual. Embora se questione por que a sociedade atual, com um elevado desenvolvimento tecnológico, ainda necessite de uma pedagogia específica que leve a uma melhoria das relações entre pessoas e ambientes. Para Seabra (2013), a civilização moderna e predominantemente urbana, em suas formas de produção e consumo, desaprendeu as possibilidades de se relacionar de forma orgânica e equilibrada com os sistemas ambientais. A indiferença com os valores e a ética ambiental passou a exigir uma retomada pedagógica quanto à ecologia e a percepção ambiental.

Leff (2009) acredita que a EA é o processo dialógico que fertiliza o real e abre as possibilidades para que se chegue a ser o que ainda não se é. Sendo o maior desafio da educação, na atualidade, a tarefa de coadjuvar o processo de reconstrução, educar para que os novos homens e mulheres do mundo sejam capazes de suportar a carga dessa crise civilizatória e convertê-la no sentido de sua existência, para o reencantamento da vida e para a reconstrução 
do mundo. Esses são os caminhos abertos para novas práxis pela racionalidade ambiental e as veias pelas quais corre o sangue da EA.

Segundo Leff (2012), a EA fomenta novas atitudes nos sujeitos sociais e novos critérios de tomada de decisões dos governos, guiados pelos princípios da sustentabilidade ecológica e diversidade cultural, internalizando-os na racionalidade econômica e no planejamento do desenvolvimento. Isso implica educar para transformar um pensamento crítico, criativo e prospectivo, para atuar no ambiente com uma perspectiva global. $\mathrm{O}$ ensino tradicional não falha exclusivamente por conta de seu aspecto disciplinar, mas por não estimular e orientar a capacidade cognitiva, inquisitiva e criativa, por conta da desvinculação dos problemas de seu contexto sociocultural e ambiental.

O Ministério da Saúde (MS), por sua vez, concebe a EA como transversal, em que deve existir uma incorporação entre as diretrizes do Sistema Único de Saúde (SUS), do Sistema Nacional de Meio Ambiente (SISNAMA), da Vigilância Ambiental, da Vigilância Epidemiológica e de outros afins. Um dos objetivos da Vigilância Ambiental é contribuir para o pressuposto de saúde como direito universal, no qual está incluído o direito ao ambiente ecologicamente equilibrado (BRASIL, 2007). Somado ao objetivo principal da Vigilância Epidemiológica, que é fornecer orientação técnica permanente aos profissionais de saúde, que têm a responsabilidade de executar ações de controle de doenças e agravos, em uma área geográfica ou população definida, constituindo-se como um importante instrumento para o planejamento, a organização e a operacionalização dos serviços de saúde (BRASIL, 2009).

Para tanto, o MS cria a Estratégia Saúde da Família (ESF) onde a atenção é focalizada na célula familiar e na comunidade, entendida e percebida a partir do seu ambiente físico e social, o que possibilita às equipes, de formação multidisciplinar, uma compreensão ampliada do processo saúde/doença e da necessidade de intervenções, que vão além de práticas curativas e hospitalocêntricas. As equipes inseridas na própria comunidade promovem, dentro da especificidade de cada realidade, valores e crenças, ações orientadas pela Política Nacional de Promoção de Saúde (BRASIL, 2014b).

Nesse contexto, entende-se que a EA é um processo de formação de cidadãos conscientes, cujos conhecimentos acerca do ambiente biofísico e seus problemas devem ser incorporados como uma ação inovadora em diferentes âmbitos. Para isto, é importante o conhecimento da realidade das famílias pelas quais a equipe de profissionais multidisciplinares é responsável, por meio do cadastramento e do diagnóstico de suas características sociais, demográficas, econômicas, epidemiológicas e ambientais (BRASIL, 2014b). Na prática, essas equipes devem estar aptas para identificar os problemas ambientais prevalentes e situações de risco às quais a população está exposta; elaborar, com a participação da comunidade, um plano local para o enfrentamento dos determinantes do processo saúde/doença; além de desenvolver ações educativas e intersetoriais.

Dessa forma, a partir da conceituação da EA torna-se essencial a abordagem de uma nova práxis, na perspectiva de novas práticas da relação homem e meio ambiente, também para a capacidade de análise crítica da problemática socioambiental. Vale ilustrar que, antes mesmo da definição da EA formulada pela Política Nacional de Educação Ambiental (PNEA), em 1999, a Conferência Sub-regional de Educação Ambiental para a Educação Secundária em Chosica/Peru (1976) caracterizou como uma ação educativa permanente pela qual a comunidade educativa tem a tomada de consciência de sua realidade global, capaz de desenvolver valores e atitudes, tanto em seus aspectos naturais quanto sociais (UNESCO, 1976).

Assim, as técnicas utilizadas no processo de formação de EA devem ser para incentivar a participação social na conjectura de uma ação política. Como tal, ela deve ser aberta ao diálogo e, ao mesmo tempo, passível ao confronto que pode gerar, visando à explicitação das 
contradições teórico-práticas subjacentes a projetos societários que estão permanentemente em disputa (SORRENTINO, 2018).

A abordagem dos conceitos tão bem elaborados sobre EA, em várias instâncias e em períodos diferentes, leva à indispensabilidade de se repensar novas ações. Para tanto, é necessário discutir os conceitos aplicados à EA e associá-los à prática de forma coerente e viável. Sendo assim, uma avaliação crítica é de grande importância para que os trabalhos e pesquisas reconhecidos como de EA ganhem consistência. A temática ambiental deve fazer parte não só da prática profissional, mas também de todo cotidiano das pessoas. Dessa forma, o papel do educador ambiental deve ser focado em propor novas posturas que garantam a qualidade de vida aos seres do planeta e sejam pautadas na ética que é perceptível em comportamentos ou atitudes das pessoas (BRASIL, 2012).

\subsection{Espaços urbanos vazios com resíduos sólidos}

Os espaços urbanos vazios são lugares das cidades que estão desabitados, sem moradores e, por isso, muitas vezes, tornam-se depósitos de resíduos e entulhos. A deposição de resíduos sólidos nesses locais tem representado sérios impactos ambientais, por facilitar a proliferação de insetos e roedores, além de repercutir em problemas de ordem social que prejudicam a qualidade de vida da população residente no entorno. Segundo o Manual de Reabilitação de Áreas Urbanas Centrais (BRASIL, 2008), vazios urbanos consistem em espaços abandonados ou subutilizados, localizados dentro da malha urbana estabelecida em uma área caracterizada por grande diversidade de espaços edificados.

Os resíduos sólidos apresentam composição bastante heterogênea e sua degradação provoca impactos socioambientais. As embalagens de plástico e de metal podem obstruir esgotos e bueiros e, assim, dificultar a evasão das águas das chuvas, acarretando em enchentes. Segundo Mazzini (2012), cerca de dezesseis milhões de pessoas no Brasil não são atendidas pelos serviços domiciliares de coleta de resíduos nas cidades, o que agrava, ainda mais, o problema, gerando assim terrenos baldios ocupados por todo tipo de resíduo descartado pelas pessoas, causando disseminação de enfermidades graves, que se tornam um grande problema de saúde pública e um desafio para a Vigilância Epidemiológica, a qual, dentre suas funções, está também combater e controlar as doenças de ordem ambiental (BRASIL, 2009).

Sabe-se que a Constituição da República Federativa do Brasil, promulgada em 1988, estabelece que:

Todos têm direito ao meio ambiente ecologicamente equilibrado, bem de uso comum do povo e essencial à sadia qualidade de vida, impondo-se ao Poder Público e à coletividade o dever de defendê-lo e preservá-lo para as presentes e futuras gerações (BRASIL, 1988, p. 203).

No entanto, verifica-se que esse direito não é respeitado em sua totalidade, seja pela omissão do Poder Público (governo), atuação das empresas (mercado) e da própria população (sociedade), mediante atividades humanas que prejudicam o meio ambiente $\mathrm{e}$, consequentemente, a qualidade de vida.

O meio urbano é um espaço que, devido à elevada quantidade de resíduos sólidos gerados pela população com as atividades diárias, condiciona o morador a observar determinados fragmentos do ambiente sem perceber situações de graves impactos ambientais. Mucelin e Bellini (2008) ressaltam que casos de agressões ambientais, como poluição visual e disposição inadequada de resíduos em terrenos baldios, refletem hábitos cotidianos em que o observador é compelido a conceber como normais.

Como tentativa de minorar esses impactos, as políticas públicas do Brasil têm adotado estratégias visando à criação de um aparelhamento jurídico que possibilite a regulação dos 
resíduos. A partir de 1988, outras leis foram promulgadas, de forma mais intensa e severa, para assegurarem e manterem o meio ambiente equilibrado, a exemplo da Lei dos Crimes Ambientais (9.605/2014) que dispõe sobre as sanções penais e administrativas derivadas de condutas e atividades lesivas ao meio ambiente, e dá outras providências (BRASIL, 2014a).

A Política Nacional de Resíduos Sólidos - PNRS (BRASIL, 2010) promulgada através da Lei n. 12.305/2010, estabelece um marco regulatório para a sociedade brasileira, por ser um instrumento de comando e controle para o tratamento de resíduos sólidos urbanos e instituir um regime de responsabilidade compartilhada sobre o ciclo de vida de diversos produtos e bens de consumo duráveis (REVEILLEAU, 2011; SILVA FILHO; SOLER, 2012; YOSHIDA, 2012). No entanto, esta Política (BRASIL, 2010) tem sido tratada pela sociedade brasileira como um ato relativamente novo do poder executivo, porém a abordagem legal da matéria ambiental e da sustentabilidade remonta há anos no país, podendo ser referenciada na Lei n. 6.938, de 31 de agosto de 1981, que dispõe sobre a Política Nacional de Meio Ambiente (PNMA) seus fins, mecanismos de formulação e aplicação (BRASIL, 1981).

A exemplo da International Solid Waste Association (ISWA), vários órgãos governamentais e não governamentais mostram-se preocupados e engajados com a problemática de resíduos sólidos. A ISWA é uma associação não governamental, sem fins lucrativos, cuja secretaria geral está em Viena (Áustria) e atua, exclusivamente, para o setor de resíduos sólidos, com o intuito de proporcionar troca de informações e experiências em âmbito global. Através dos seus Grupos de Trabalho (GTs), a ISWA auxilia organismos internacionais, como o Programa das Nações Unidas para o Meio Ambiente (PNUMA), a Organização Mundial da Saúde (OMS) e a União Europeia com relatos técnicos e opiniões sobre as práticas de gestão de resíduos sólidos. Em 2018, havia dez GTs concentrados em diferentes áreas de gestão de resíduos sólidos: aterros, tratamento biológico de resíduos, resíduos perigosos, tecnologias de coleta e transporte, resíduos de saúde, comunicação, questões legais, reciclagem e minimização de resíduos, recuperação energética e mudanças climáticas (ISWA, 2018).

No local de estudo desta pesquisa, Campina Grande, segunda cidade mais populosa do Estado da Paraíba, a gestão dos resíduos sólidos é de responsabilidade da Secretaria de Serviços Urbanos e Meio Ambiente (SESUMA). Para tanto, foi elaborado um Plano Municipal de Gestão Integrada de Resíduos Sólidos - PMGIRS (CAMPINA GRANDE, 2014) que apresenta diretrizes e estratégias que visam propiciar condições para o alcance dos objetivos dispostos na Política Nacional de Resíduos Sólidos - Lei 12.305/2010 - tomando como referência formulações do Ministério do Meio Ambiente em seu Plano Nacional (BRASIL, 2010).

Campina Grande realiza coleta regular de resíduos sólidos (sendo todos os dias no centro da cidade e nas principais avenidas e, em dias alternados, nos bairros) com abrangência em toda área urbana. Mesmo assim, verifica-se, em vários bairros, a existência de terrenos baldios ocupados por resíduos sólidos gerados em residências, estabelecimentos comerciais e industriais. Esses resíduos advêm da própria comunidade que reside ou trabalha no entorno e, costumeiramente, faz a deposição nesses locais de forma que os órgãos públicos não conseguem combater.

No contexto de Campina Grande, no PMGIRS (2014) foram consideradas variáveis que incluem as taxas de crescimento populacional, em conjunto com fatores como mudanças de hábitos de consumo, migrações etc., as quais repercutem diretamente no aumento da geração de resíduos.

O horizonte de tempo considerado foi de 2015 até 2035, sendo possível mostrar cenários futuros, bem como gerar parâmetros para dimensionamento dos sistemas que venham a ser futuramente implantados. Além disso, procurou-se incorporar as sugestões feitas pela população, por meio de representantes das Sociedades de Amigos de Bairros (SAB's) de Campina Grande durante a realização das oficinas do PMGIRS-CG, que ocorreram em janeiro de 2014. 
As diretrizes foram definidas para cada tipo de resíduo sólido gerado no município, devendo ser implementadas por todos os atores envolvidos com a execução da PNRS, ou seja, a responsabilidade pelas estratégias é compartilhada entre o poder público, a sociedade e os geradores dos resíduos sólidos. As diretrizes e estratégias estabelecidas, relativas aos resíduos sólidos urbanos buscam: o atendimento aos prazos legais; o fortalecimento das políticas públicas conforme o previsto na Lei n. 12.305/2010; a melhoria da gestão e do gerenciamento dos resíduos sólidos como um todo; o fortalecimento do setor de resíduos sólidos e as interfaces com os demais setores da economia da cadeia logística dos resíduos sólidos (CAMPINA GRANDE, 2014).

O PMGIRS de Campina Grande (2014) adota como diretriz principal a não geração, redução e máxima recuperação de resíduos e a minimização da quantidade de rejeitos levados à disposição final ambientalmente adequada, considerando a inserção socioeconômica dos catadores de materiais recicláveis e reutilizáveis, e as formas de responsabilidade dos setores públicos e privados, que são evidenciadas da diretriz principal do Plano Nacional de Resíduos.

Para o cumprimento da diretriz que visa o atendimento a $100 \%$ da população urbana e distritos com coleta de resíduos sólidos domiciliar foram adotadas as seguintes estratégias: implantar a coleta em todos os domicílios com frequência adequada e coleta regular; fiscalizar a implantação da coleta de resíduos domiciliares; monitorar os serviços de coleta domiciliar; estabelecer programas de controle social com informações à população sobre a quantidade de resíduos coletados, aterrados, de coletas seletivas e coletas especiais; inserir a educação ambiental no projeto político pedagógico das escolas em todo o município, englobando as instituições de educação superior (CAMPINA GRANDE, 2014).

Por ser um tema transversal (BRASIL, 2007), a educação ambiental é incluída em conteúdos de disciplinas obrigatórias, e são realizadas campanhas educativas por meio de gincanas, feira de ciências e divulgações sobre a reciclagem e preservação do meio ambiente.

No entanto, apesar de o PMGIRS de Campina Grande (2014) estar sendo executado, ainda prevalecem os espaços urbanos vazios, ocupados por resíduos sólidos em diversos bairros distribuídos na cidade, fato este que independe de falhas em saneamento básico e em poder aquisitivo das pessoas que habitam no entorno, tornando essa problemática em forte desafio para a gestão municipal resolver.

\section{Metodologia}

A metodologia da pesquisa, em função do objetivo, configura uma abordagem indutiva, iniciando-se pela fase exploratória, que consiste em uma caracterização do problema, do objeto, dos pressupostos, das teorias e do percurso metodológico, cuja trajetória foi por meio de procedimentos e estratégias heterogêneas. A forma mais viável e permissiva para obtenção de informações e dados radica no trabalho de campo, realizado após aprovação pelo Comitê de Ética em Pesquisa do Centro de Ensino Superior e Desenvolvimento (CESED), via Plataforma Brasil, com número do Certificado de Apresentação para Apreciação Ética (CAAE) 97426918.1.0000.5175.

A pesquisa foi realizada entre os meses de julho a outubro de 2018, no município de Campina Grande, situado no agreste do estado da Paraíba, ficando a $120 \mathrm{~km}$ da capital, João Pessoa. De acordo com estimativas do Instituto Brasileiro de Geografia e Estatística (IBGE, 2020) o município conta com uma população de 411.807 habitantes distribuídos em 51 bairros. No campo da saúde, Campina Grande é dividida geograficamente em oito Distritos Sanitários (DS), os quais são demarcados a partir de características epidemiológicas, sociais e suas necessidades, e dos recursos de saúde para atendê-la.

Como instrumento para coleta de dados foi utilizada uma câmara de celular (Smartphone), através da qual foram criados registros fotográficos dos terrenos baldios, 
submersos em resíduos sólidos dos mais variados. Somada aos registros fotográficos, foi aplicada uma entrevista semiestruturada, sob a coordenação das Vigilâncias Ambiental e Epidemiológica. Assim, relacionando o (re)trato da educação ambiental e analisados os desafios, as ações e o enfrentamento dessas Vigilâncias em uma perspectiva de transformar a relação entre a sociedade e meio ambiente.

A construção do corpus empírico foi realizada a partir da observação direta (in loco) das fotografias e, posteriormente, descritos os achados utilizando a análise de conteúdo de Bardin (2015) na tentativa de alcançar o objetivo traçado para este estudo. Para as informações colhidas nas Vigilâncias Ambiental e Epidemiológica considerou-se, como critérios de inclusão, a associação de doenças notificadas e evidenciadas pelo contato ou convívio com resíduos sólidos. A compreensão do sentido da entrevista qualitativa, de seus limites e potenciais, bem como a preparação para a sua execução foram ancoradas nas recomendações de Gaskell (2013). Um tópico guia foi construído para orientar as entrevistas, levando em consideração os aspectos territoriais, ambientais e os modos de vida nas comunidades mais afetadas.

Com base no princípio de saturação empírica (MINAYO, 2017), quando se percebe a consistência das informações centrais e a relativa redundância de eventuais novas fotografias, atingiu-se um número de registros fotográficos, pois foi observado a mesma tendência nos oito DS. Saturação é um termo criado por Glaser e Strauss (1967) para se referir a um momento no trabalho de campo em que a coleta de novos dados não traz mais esclarecimentos para o objeto estudado.

Assim, foi registrado um total de 89 imagens, das quais, apenas seis foram selecionadas para este estudo, utilizando-se, como critério de inclusão, terrenos baldios com até vinte metros de distância de residências e a associação de doenças notificadas na Vigilância Epidemiológica relacionadas aos moradores do entorno, como dengue, zika, chicungunya, leptospirose, tétano e diarreia. Os trabalhos de campo proporcionaram, também, oportunidade para diferentes observações e registros de notas, conjunto que, inevitavelmente, auxiliou na abordagem ora apresentada.

O percurso da coleta de dados foi em três etapas: a primeira etapa foi a visita junto à Vigilância Ambiental em busca de mapas geográficos de terrenos baldios com o objetivo de detectar áreas mais críticas em cada DS, distribuídos no município em estudo, além da realização da entrevista com a coordenação. A segunda etapa foi na Vigilância Epidemiológica, a fim de captar dados secundários oriundos de registros no Sistema de Informação em Saúde com maiores casos de notificações de doenças relacionadas à exposição de resíduos sólidos, transmitidas por insetos e roedores como moscas, mosquitos, ratos e baratas. Ademais, também foi realizada a entrevista com a coordenação. E, a terceira etapa, consistiu na realização de visitas aos terrenos baldios existentes nos oito DS, onde pôde-se detectar e registrar fotograficamente a evidência de resíduos sólidos depositados em espaços urbanos vazios. Conjuntamente, foi realizada uma pesquisa bibliográfica para embasamento teórico dos autores que remetem à educação ambiental como ferramenta primordial à preservação do ecossistema.

As Vigilâncias Ambiental e Epidemiológica localizam-se em prédios diferentes e em bairros distanciados. Para a realização da pesquisa, foram necessárias várias visitas em ambas as Vigilâncias. A primeira para apresentar o projeto, explanar os objetivos do estudo e escolher a melhor forma de registrar a coleta de dados, além de solicitar a autorização por escrito para a realização da pesquisa (carta de anuência); as demais visitas foram para agendamento da entrevista, assinatura do Termo de Consentimento Livre e Esclarecido (TCLE) e realização da entrevista e coleta de dados no sistema de informação.

\section{Resultados e Discussões}


Conforme dados fornecidos pelas Vigilâncias Ambiental e Epidemiológica em relação à distribuição geográfica dos DS de Campina Grande, foi realizada uma visita nos bairros mais afetados com casos notificados de manifestação de doenças ocasionadas pelo convívio ou contato com resíduos sólidos.

A Figura 1 mostra um terreno baldio, a poucos metros de residências, com acúmulo de resíduo domiciliar, atitude que parece ser uma prática comum por parte daquela população. Os terrenos baldios são espaços das cidades que estão vazios, sem moradores e, por isso, muitas vezes, tornam-se depósitos de resíduos e entulhos de todas as classificações, causando um mau cheiro no entorno, depreciando a área e atraindo animais que são vetores de doenças (SOUZA; SOUZA, 2013).

Na Figura 2, pode-se perceber o acúmulo de resíduos orgânicos, plásticos, papéis, garrafas pet, entre outros, dispersos e em degradação, fato que pode ser visualizado em várias regiões do país. Em uma pesquisa realizada em Chapecó (SC) foram encontrados resíduos sólidos urbanos em 72 dos cem terrenos baldios avaliados, sendo resíduos de origem residencial, observados com maior frequência e de forma heterogênea entre as regiões da cidade (NEVES; LUTINSKI; TIBURSKI, 2018).

Figura 1- Terreno baldio com deposição de resíduo domiciliar, bairro Catolé - Campina Grande-PB.

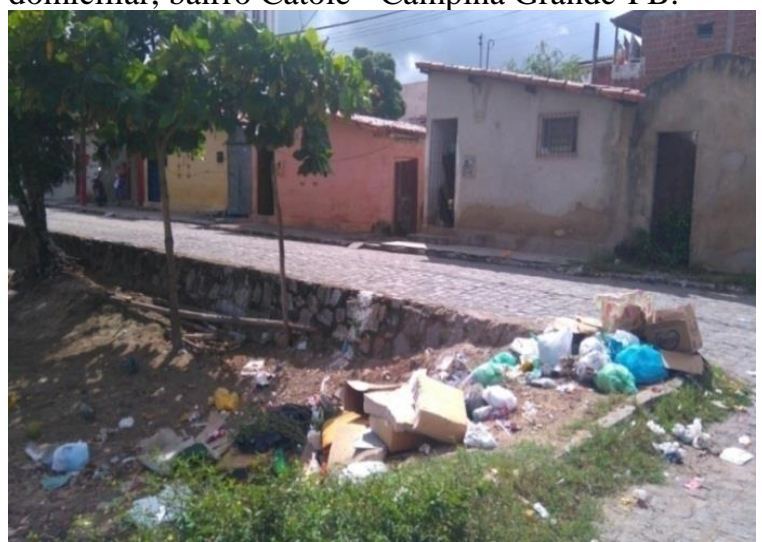

Fonte: Imagem própria da pesquisa (2018)
Figura 2- Rua Maestro Honório, bairro Alto Branco Campina Grande-PB.

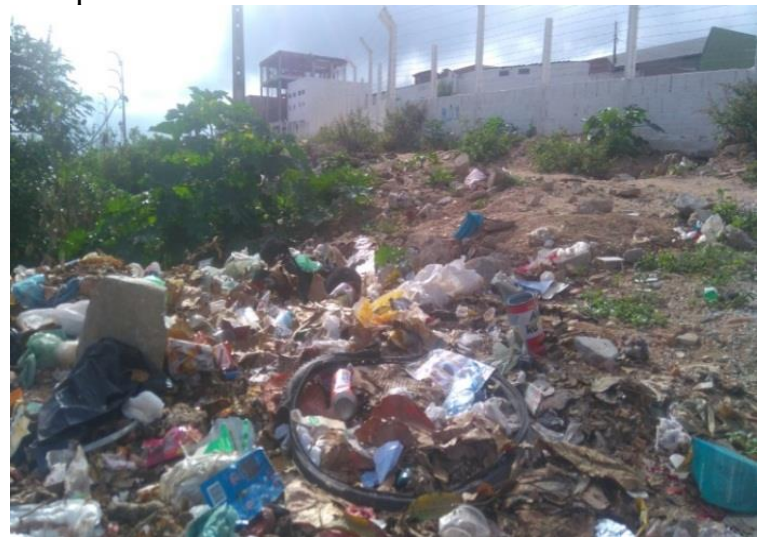

Fonte: Imagem própria da pesquisa (2018)

Para a Vigilância Epidemiológica, a falta de limpeza nesses terrenos pode gerar problemas diversos em virtude desses acúmulos, como o crescimento de plantas que sirvam de moradia e esconderijo de animais peçonhentos, além de facilitar a proliferação de roedores e insetos, mau cheiro no ambiente e a presença de pessoas que fazem uso indevido do local. Outro problema ocasionado pela presença desses detritos nos terrenos abandonados ocorre em épocas de chuva, quando a enxurrada pode carregá-los, resultando em entupimento de bueiros e canais de escoamento de água, provocando alagamentos na região.

O Diagnóstico do Manejo de Resíduos Sólidos Urbanos, realizado através do Sistema Nacional de Informações sobre a Gestão de Resíduos Sólidos (SINIR) identifica os aspectos da gestão dos serviços de manejo dos resíduos sólidos nos municípios brasileiros. Em 2016, 65,9\% dos municípios brasileiros (3.670) participaram do Diagnóstico, representando $84 \%$ da população urbana do país (146,3 milhões de pessoas). O documento revela que $98,6 \%$ dessa população urbana teve cobertura do serviço regular de coleta de resíduos domiciliares, enquanto aproximadamente 2,7 milhões de habitantes do país sofrem com o déficit da coleta desses resíduos, sendo 44,7\% moradores da região Nordeste, $21,8 \%$ do Sudeste, $21,1 \%$ do Norte e $12 \%$ dessa população dividida entre as regiões Sul e Centro-Oeste (BRASIL, 2018). 
Aprovada em 2015, na Cúpula de Desenvolvimento Sustentável, em Nova Iorque, a Agenda 2030 da ONU é "um plano de ação para as pessoas, o planeta e a prosperidade" que almeja "assegurar os direitos humanos de todos" (ONU, 2015, p. 1). O documento intitulado de Transformando Nosso Mundo: A Agenda 2030 para o Desenvolvimento Sustentável apresenta 169 metas, distribuídas em dezessete objetivos, os quais são normas pertencentes aos Regimes Internacionais do Meio Ambiente e do Desenvolvimento, e busca "assegurar padrões de produção e de consumo sustentáveis" (ONU, 2015, p.31), que visam prevenir, reduzir, reciclar e reusar os resíduos de modo geral.

A Parceria Internacional para a Expansão de Serviços de Gestão de Resíduos para Autoridades Locais (IPLA), promovida pela United Nations Centre for Regional Development, possibilita a expansão dos serviços locais de gestão de resíduos ao acelerar a implantação da infraestrutura necessária e de serviços em seus vários níveis de gestão, tais como a não geração, a prevenção, a minimização, a segregação, a coleta, o transporte, o reuso, a reciclagem, a recuperação, o tratamento e a disposição (UNCRD, 2018).

A Figura 3 retrata a Pedreira, lixão do antigo bairro Prado, hoje Catolé. Segundo informações de moradores antigos do lugar, existia no local, há algumas décadas, uma vala onde as famílias despejavam seus resíduos domiciliares. Esse ambiente foi desativado e aterrado pela prefeitura, sendo, em seguida, construída uma escola municipal, uma Unidade Básica do Programa Saúde da Família (PSF) e uma igreja. Apesar de esse terreno ter sido desativado para a deposição de resíduos sólidos há décadas, os moradores mantiveram o hábito de fazer descartes irregulares, demonstrando ser uma questão cultural e de comportamento ecológico.

Em uma pesquisa realizada em Curitiba (PR) foi possível compreender que a formação de atitudes de reflexão é essencial para garantir o sucesso da educação ambiental. Some-se a isso, a necessidade de dotar profissionais de mais subsídios teóricos e metodológicos, para que possam promover aprendizagens mais significativas por meio das práticas em educação ambiental, apontando, assim, a relevância de trabalharem com os problemas locais, além de permitir um envolvimento maior deles nessas questões, trazendo reflexões imprescindíveis para a problemática ambiental, sendo elas, culturais, sociais, econômicas, políticas e históricas (OLIVEIRA; SAHEB; RODRIGUES, 2020).

A Figura 4 revela o acúmulo de objetos que facilitam a proliferação de insetos transmissores de doenças como a dengue, zika, chicungunya e diarreias. Segundo informações colhidas no momento dos registros fotográficos, vários moradores do entorno foram acometidos por essas doenças, trazendo repercussões sociais, pois além do adoecimento, ficaram impossibilitados em manter sua rotina diária, como frequentar escola e trabalho. Os moradores também informaram que esses terrenos têm servido como cemitério para animais mortos, provocando sérios impactos ambientais, atraindo insetos e causando mau cheiro. 
Figura 3- Terreno baldio com resíduo domiciliar e podas de árvores, bairro Prado - Campina Grande-PB

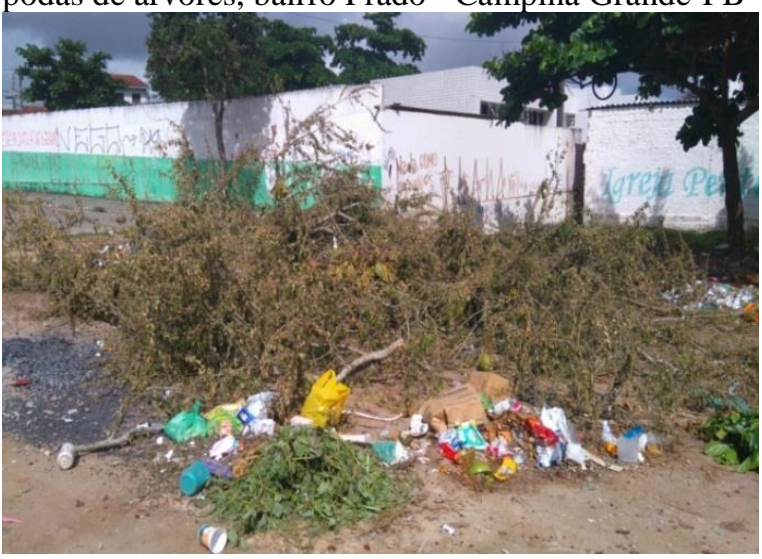

Fonte: Imagem própria da pesquisa (2018)
Figura 4- Rua Cassiano Pereira, bairro Jardim Paulistano - Campina Grande-PB.

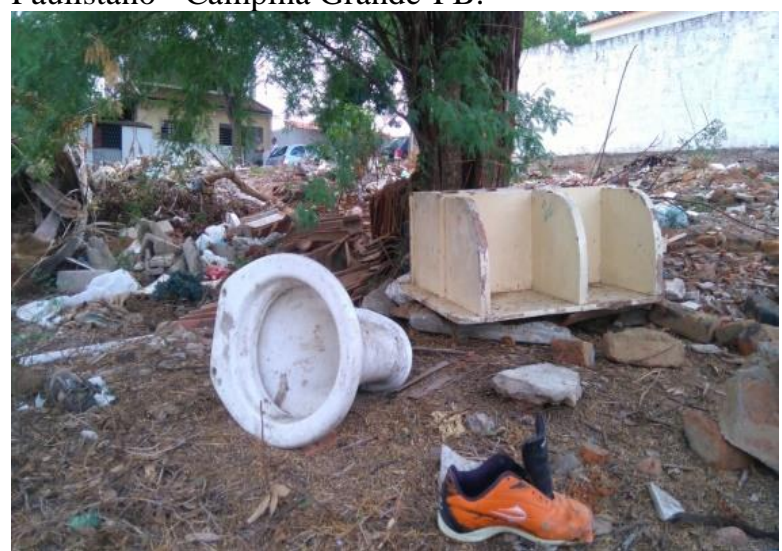

Fonte: Imagem própria da pesquisa (2018)

Moraes et al. (2017), defendem que o aumento da geração de resíduos sólidos é causado pela produção e pelo consumo de bens em larga escala, que é a base do modelo de crescimento econômico do sistema capitalista. Leff (2012) chama esse processo de crise ambiental, que deu origem a um questionamento da racionalidade econômica dominante, assim como as ciências do conhecimento caracterizadas pelo domínio do homem sobre a natureza. Leff (2012) também refere que a complexidade ambiental inaugura uma nova pedagogia, implicando uma reapropriação do conhecimento, chamada de pedagogia ambiental, a qual não é a da sobrevivência, do conformismo e da vida cotidiana (numa perspectiva conservacionista e romântica), mas uma educação embasada na imaginação criativa de uma nova racionalidade.

Não se deve preparar as gerações para conhecerem as incertezas dos desastres ecológicos, e nem tão pouco gerar capacidade de respostas para o imprevisto; deve-se, sim, preparar novas mentalidades que compreendam as inter-relações entre processos complexos e que desenvolvam habilidades necessárias para a inovação e a construção do inédito (LEFF, 2012) para, com isso, permitir a participação ativa do ser nos processos de tomada de decisão que conduzam à gestão ambiental ecologicamente sustentável.

No percurso da pesquisa foi identificada uma rua sem saída, fechada por um terreno baldio no bairro Conceição. À sua frente havia um automóvel (Kombi) que, segundo informações de moradores, estava há aproximadamente cinco anos naquele lugar (Figura 5), sendo ponto de consumo de drogas. Em destaque está uma placa com a frase: proibido jogar lixo neste local.

A Figura 6 exibe resíduos domiciliares e eletroeletrônicos, os quais são altamente nocivos ao meio ambiente por conter materiais corrosivos como pilhas, baterias e outros elementos como plástico e metal que são de longa durabilidade e de difícil degradação.

Figura 5- Rua Juvêncio Martins de França, bairro Conceição - Campina Grande-PB.

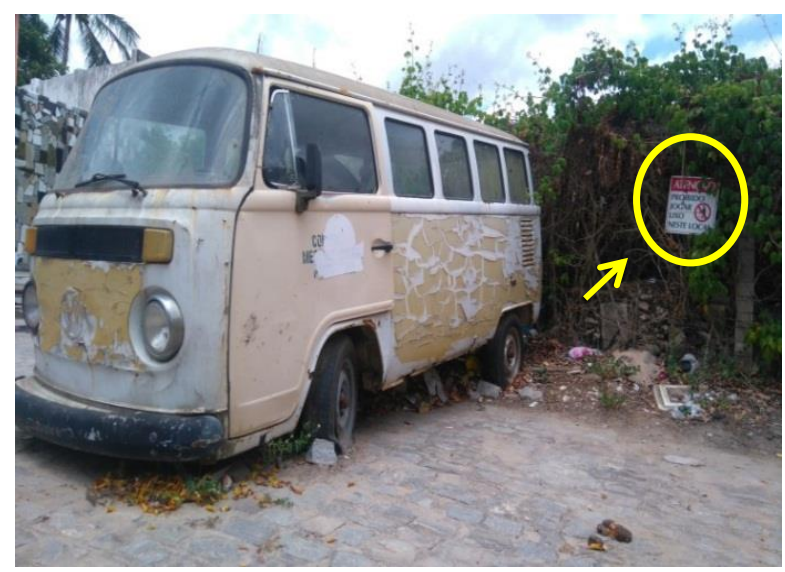


Fonte: Imagem própria da pesquisa (2018)

Figura 6- Rua Quintino Leôncio de Castro, bairro Sandra Cavalcante - Campina Grande-PB.

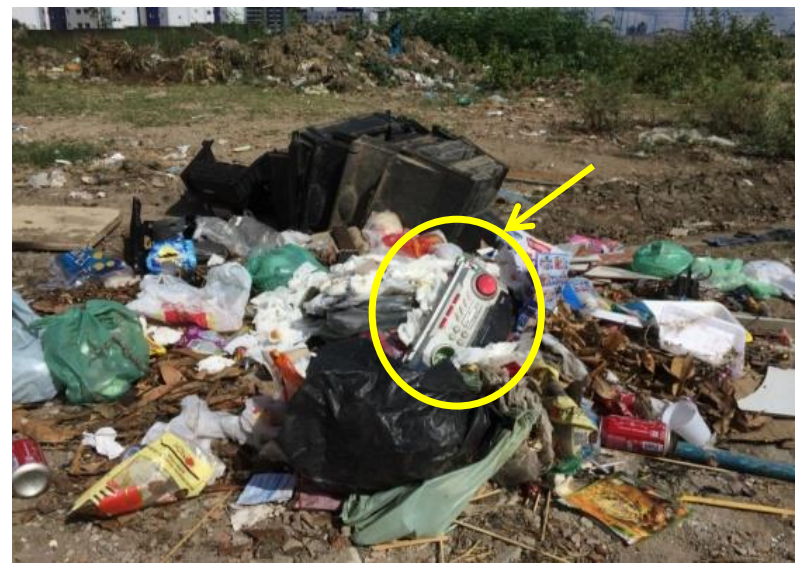

Fonte: Imagem própria da pesquisa (2018)

Em Chapecó (SC), uma pesquisa realizada por Neves, Lutinski e Tiburski (2018) revelou que a frequência da disposição de resíduos em terrenos baldios vem aumentando pela diversidade cada vez maior das atividades e demandas humanas. A carência de ações de educação ambiental voltadas para a sensibilização da população quanto à gestão ambientalmente correta dos resíduos de origem doméstica pode explicar a elevada ocorrência de resíduos dessa natureza nos terrenos baldios (JACOBI, 2003). A frequência com que foram registrados RSU da construção civil e de origem comercial indicam fragilidades no processo de fiscalização pelos órgãos responsáveis.

Materiais como papéis, plásticos, metais, pneus, vidros, espumas, madeiras e isopor podem ser reciclados ou reutilizados para outras finalidades, reduzindo, assim, o impacto ambiental sobre as fontes primárias desses recursos na natureza. A separação adequada, na origem, pode evitar a contaminação dos resíduos e agregar maior valor aos RSU recicláveis (NEVES; ; LUTINSKI; TIBURSKI, 2018).

Mesmo não tendo casos notificados com doenças relacionadas a resíduos sólidos, alguns outros terrenos baldios, em bairros considerados de padrão econômico alto, foram visitados, porém encontravam-se limpos no momento da pesquisa. Talvez, o fator socioeconômico tenha relevância quanto à consciência e sensibilidade em preservar o ambiente.

As imagens reveladas neste estudo mostram o retrato da EA, bem como a real necessidade de se tratar essa temática com uma nova práxis, de forma que o seu verdadeiro papel seja reconhecido como necessário e difundido pela sociedade. Para Pereira (2018) existe um alto custo de uma má gestão de resíduos sólidos, assim como a economia feita com uma gestão eficaz. A integração do governo com a iniciativa privada e a sociedade civil, por meio da EA e das Tecnologias Sociais, representa um importante passo para a superação dos desafios encontrados (ONU, 2015).

A coordenação da Vigilância Ambiental do município em estudo conta com mais de sete anos de atuação no cargo. No momento da pesquisa foram feitos vários questionamentos sobre a dispersão de terrenos baldios distribuídos na cidade; a problemática de resíduos sólidos nesses terrenos; a Vigilância Ambiental atribui esse comportamento das pessoas ao quê; quais são as advertências e punições que a gestão pratica diante do poluidor; sobre os indicadores sociais, econômicos e ambientais que mais prejudicam a efetividade das ações e serviços dessa Vigilância e, ainda, quais as ações para mitigar resíduos em terrenos baldios.

A coordenação da Vigilância Ambiental entende que as pessoas depositam os resíduos sólidos em terrenos baldios por falta de informação do perigo à saúde e por omissão de educação e responsabilidade com o outro. Assim, os principais problemas enfrentados são aumento de focos de mosquitos, ratos, baratas entre outros.

Para mitigar o depósito de resíduos sólidos em locais impróprios, a Vigilância Ambiental tem promovido ações educativas específicas a essa problemática. No entanto, os indicadores ambientais que mais prejudicam a efetividade das ações e serviços são domicílios 
improvisados; precário saneamento básico; animais domésticos sem os cuidados adequados; educação ambiental inconsistente e terrenos baldios sem as devidas manutenções de seus responsáveis, além disso, as pessoas parecem não dar a atenção adequada às advertências dos agentes de campo.

A coleta de dados na Vigilância Epidemiológica foi realizada com a coordenação que atua há seis anos no serviço. As perguntas foram semelhantes às da Vigilância Ambiental, acrescentando apenas informações relacionadas à notificação de doenças transmitidas por insetos e roedores.

Para essa coordenação, o principal problema ocasionado pelos terrenos baldios com resíduos tem sido o aumento de notificação compulsória de doenças correlacionadas. A coordenação da Vigilância Epidemiológica acredita que as pessoas depositam seus resíduos nesses locais por falta de cultura relacionada à preservação ambiental e falhas na educação doméstica. Afirma, ainda, que a população recebe orientações sobre EA por meio do trabalho de equipes do PSF que fazem palestras na Unidade de Saúde, em escolas e instituições onde são convidadas. Essas palestras são intensificadas em períodos de campanhas.

Amparada na PNMA (1981) e no PMGIRS (CAMPINA GRANDE, 2014), a coordenação da Vigilância Epidemiológica foi questionada sobre o cumprimento e a autuação do Princípio do Poluidor Pagador, a qual referiu que desconhece casos de moradores que já tenham sido advertidos por fiscais da prefeitura e/ou pagaram algum tributo porque estavam depositando resíduos sólidos em terrenos baldios.

Para a Vigilância Epidemiológica, os indicadores sociais, econômicos e ambientais que mais prejudicam e desafiam a efetividade das ações e serviços coincidem com os problemas da Vigilância Ambiental, ou seja, domicílios improvisados; precário saneamento básico; analfabetismo ou baixa escolaridade do chefe da família; falhas na educação ambiental; terrenos baldios sem os devidos cuidados de seus responsáveis e, ainda, disseminação de doenças provocadas por insetos e roedores.

É importante ressaltar que, na pesquisa de campo, foram observados terrenos baldios nos oito DS, sendo de maior número em bairros considerados de médio e alto padrão econômico. Porém, alguns estavam limpos no momento da pesquisa, o que não foi visto em terrenos baldios situados em bairros mais carentes economicamente, pois estavam, em sua maioria, com resíduos sólidos ou pontos com a formação de pequenos lixões.

Conforme Mattos, Anello e Tagliani (2013), a formação de pequenos lixões causa contaminação do solo e da água superficial e subterrânea, dispersão de plásticos e outros materiais por ação do vento e intempéries, proliferação de insetos e vetores que afetam a saúde humana, além de produzir um impacto visual negativo, com consequente desvalorização de propriedades vizinhas.

A fim de reduzir a prática da deposição de resíduos sólidos em terrenos baldios, a Vigilância Epidemiológica sugere continuar nas campanhas de EA promovidas também pela Secretaria de Serviços Urbanos e Meio Ambiente - SESUMA e pela Vigilância Ambiental, além de investir na EA de crianças e transversalizar esse tema em todos os conteúdos escolares. Continuadamente, tanto a Vigilância Epidemiológica quanto a Ambiental fazem palestras e capacitações com os profissionais do PSF sobre todos os tipos de resíduos sólidos e preservação ambiental.

A Declaração da Primeira Conferência Intergovernamental sobre Educação Ambiental, em Tbilisi, 1977, diz que:

A Educação Ambiental deve ser dirigida à comunidade, despertando o interesse do indivíduo em participar de um processo ativo no sentido de resolver problemas dentro de um contexto de realidades específicas, estimulando a iniciativa, o senso de responsabilidade e o esforço para construir um futuro melhor. (...) pode ainda 
contribuir satisfatoriamente para a renovação do processo educativo e que o objetivo da Educação Ambiental deva estar concentrado no desenvolvimento de uma compreensão integrada do meio ambiente em suas múltiplas e complexas relações (CONFERÊNCIA INTERGOVERNAMENTAL SOBRE EDUCAÇÃO AMBIENTAL, 1977).

Assim, a EA deve ser direcionada para a cidadania ativa, considerando seu sentido de pertencimento e corresponsabilidade que, por meio da ação coletiva, busca a compreensão e a superação das causas estruturais dos problemas ambientais, pois o saber popular consegue proporcionar caminhos de participação para a sustentabilidade (BRASIL, 1999).

Para Costa e Loureiro (2019), conhecer e reconhecer os problemas do mundo exige uma reforma no pensamento, que necessita da contextualização do conhecimento. Por conseguinte, a relação do homem com a natureza não pode ser fragmentada. $\mathrm{O}$ pensamento, consciência e cultura se diferenciam e se confundem, ao mesmo tempo, com a natureza física. Isso sugere aos processos de EA uma reflexão sobre a dinâmica da relação sociedade-natureza, pois, sem essa dimensão, o debate ambiental se torna simplificado, fragmentado e despolitizado pela negação da materialidade e das contradições contidas nas relações sociais.

Necessário se faz intensificar a adoção de medidas educativas e conscientizadoras. Talvez, os indispensáveis atores nesse processo sejam os profissionais de saúde e de educação, insistindo, juntos, em realizar uma educação continuada mais eficaz com vigilância de hábitos da comunidade assistida.

Com base em um estudo investigativo sobre a sistematização das Estratégias de Ensino (EE) com foco na EA foi possível evidenciar, a partir dos resultados obtidos, certa carência quanto ao entendimento da EA no contexto educacional, ainda pouco explorada pelos professores. A problematização das práticas de EA decorre da necessidade que sejam introduzidas no cotidiano escolar, na perspectiva da adoção de hábitos mais saudáveis. A sistematização das EE com foco na EA ainda é um desafio que precisa avançar, a começar pelo planejamento, pela ação e pela avaliação no coletivo escolar entre os professores, tendo em vista o cuidado da própria ação docente (UHMANN; VORPAGEL, 2018).

Para Leff (2009), o saber ambiental é uma epistemologia política que busca dar sustentabilidade à vida; constitui um saber que vincula os potenciais ecológicos e a produtividade neguentrópica do planeta com a criatividade cultural dos povos que o habitam. O saber ambiental muda o olhar do conhecimento e, com isso, transforma as condições do saber no mundo na relação que estabelece o ser com o pensar e o saber, com o conhecer e o atuar no mundo.

Novas práxis na perspectiva da complexidade ambiental não apenas levam à necessidade de aprender fatos novos (mais complexos), defende Leff (2009), mas, também, inauguram uma nova pedagogia, que implica na reapropriação do conhecimento desde o ser do mundo e do ser no mundo, por meio do saber e da identidade que se forjam e se incorporam ao ser de cada indivíduo e cada cultura.

Leff (2009) ainda refere que toda aprendizagem implica uma transformação do conhecimento a partir do saber que constitui o ser. A pedagogia da complexidade ambiental reconhece que apreender o mundo nasce do ser de cada sujeito; essa aprendizagem consiste em um processo dialógico que transborda toda racionalidade comunicativa construída sobre a base de um possível consenso de sentidos e verdades. A pedagogia ambiental abre o pensamento para compreender o ambiente, através do potencial ecológico da natureza e dos sentidos culturais que mobilizam a construção social da história.

A EA, no âmbito formal e não formal, é determinante e primordial na garantia de padrões ambientais adequados, possibilitando assumir e incorporar aos nossos fazeres diários uma gama de responsabilidades que nos levem a uma nova postura, tendo como consequência a tomada de atitudes, na construção de sociedades ecologicamente equilibradas e socialmente 
sustentáveis e justas (JACOBI, 2003). Para esse autor, isso só é possível a partir da consciência ambiental, centralizada no exercício da cidadania e nos valores éticos e morais, individuais e coletivos, numa perspectiva segura para o desenvolvimento sustentável.

A PNEA (BRASIL, 1999) defende que um dos princípios da EA seja despertar a preocupação individual e coletiva para a situação ambiental, garantindo o acesso à informação em linguagem adequada e compreensível, além de desenvolver uma consciência crítica, sensibilização e estímulo ao enfrentamento das questões ambientais e sociais. Provavelmente, para se alcançar esse processo de desenvolvimento, deve-se procurar atentar não apenas à mudança cultural, mas, também, à transformação coletiva, entendendo que o comprometimento ambiental é uma questão ética, social, cultural e política.

\section{Conclusões}

As estampas das pinturas representadas nas fotografias permitem revelar a necessidade de se retratar a EA considerada imprescindível para o desenvolvimento sustentável, possibilitando um ecossistema saudável para gerações presentes e futuras. Falhas no ensino da EA são gritantes, tornando um entrave à socialização das pessoas em um contexto socioambiental dentro do ecossistema, evidenciada na ausência de respeito e responsabilidade com o meio ambiente, necessárias à sobrevivência da humanidade.

Quanto maior o nível de EA de uma comunidade, mais eficazes serão as ações que visam à promoção da saúde, à prevenção de doenças e à conservação dos recursos naturais. Para tanto, faz-se necessário um trabalho de conscientização e sensibilização da população no sentido de entender a obrigação de defender e cuidar do ambiente e não depositar resíduos sólidos em terrenos baldios, sejam eles públicos ou privados.

É importante o incentivo a projetos de intervenção na realidade das escolas de todos os níveis educacionais, no tocante à nova práxis na EA, para a consolidação de uma prática educativa que desenvolva valores diferentes em relação à forma como vemos, sentimos e vivemos.

A resposta de como a EA poderia resolver um dos sérios problemas ambientais, como a deposição de resíduos em terrenos baldios, de fato, ainda é bastante subjetiva. No entanto, sabese que a EA, apenas, não resolveria, mas minimizaria os efeitos drásticos que o ambiente e a própria população enfrentam. Evidentemente, a gestão também tem a sua inegável contribuição na manutenção de um ambiente saudável e habitável. E, ainda, deve-se contar com a constante conservação dos terrenos baldios, cuja responsabilidade é de seus proprietários.

A EA precisa ser desenvolvida nas escolas, em todas as séries até no ensino superior, de maneira contínua e permanente, e por meio de palestras oferecidas pelos profissionais de saúde, sobretudo aqueles que atuam em comunidades, pois estes têm conhecimento dos problemas que afetam a saúde de sua população.

Propõe-se, neste estudo, que esses profissionais sejam estimulados a um maior engajamento na EA e, juntamente com as comunidades, elenquem e avaliem, dentro de cada contexto, os problemas ambientais; apresentem à população os malefícios que resíduos sólidos dispersos podem acarretar; realizem dinâmicas de grupo com intuito de sensibilizar a população, levando a um envolvimento emocional diante das situações em que se encontram e proponham mudanças de atitudes. Para isso, os profissionais dispõem de várias metodologias, inclusive ferramentas tecnológicas como o Padlet.

A Vigilância Ambiental do município em estudo sugere notificações e multas aos negligentes com o ambiente, bem como fazer valer o Código de Postura do município. Com essa mesma perspectiva, a Vigilância Epidemiológica recomenda fazer campanhas mais impetuosas que estimulem práticas de EA, e para isso, precisa contar com as atribuições de profissionais da educação e da saúde. 
Amparado nessas sugestões, acredita-se que este estudo venha contribuir para identificação de aspectos específicos de culturas e comportamentos ecológicos em um ambiente, servindo como ponto de partida para elaboração de instrumentos que permitam a compreensão desses constructos no âmbito populacional.

\section{Referências}

BARDIN, L. Análise de Conteúdo. São Paulo: Edições 70, 2015.

BECK, U. World at Risk. Cambridge: Polity Press, 2009.

BRASIL. Lei $n^{\circ}$ 6.938, de 31 de agosto de 1981. Dispõe sobre a Política Nacional do Meio Ambiente (PNMA), seus fins e mecanismos de formulação e aplicação, e dá outras providências. Brasília: Casa Civil, 1981. Disponível em: <http://www.planalto.gov.br/ccivil_03/leis/16938.htm>. Acesso em: 11 jun. 2021.

BRASIL. Constituição Federal. Promulgada em 5 de outubro de 1988. Brasília - DF: Centro Gráfico, 1988.

BRASIL. Lei $n^{o}$ 9.795, de 27 de abril de 1999. Dispõe sobre a educação ambiental, institui a Política Nacional de Educação Ambiental e dá outras providências (PNEA). Brasília: Casa Civil, 1999. Disponível em: <http://www.planalto.gov.br/ccivil_03/leis/19795.htm〉. Acesso em: 11 jun. 2021.

BRASIL. Ministério da Saúde. Conselho Nacional de Saúde. Subsídios para a construção da Política Nacional de Saúde Ambiental - Brasília: Ministério da Saúde/ CNS, 2007.

BRASIL. Manual de Reabilitação de Áreas Urbana Centrais. Brasília: Ministério das Cidades, 2008.

BRASIL. Ministério da Saúde. Secretaria de Vigilância em Saúde. Departamento de Vigilância Epidemiológica. Guia de Vigilância Epidemiológica - 7. ed. - Brasília: Ministério da Saúde, 2009.

BRASIL. Lei 12.305/2010, de 02 de agosto de 2010. Dispõe sobre a Política Nacional de Resíduos Sólidos. Brasília: Casa Civil, 2010. Disponível em: <http://www.planalto.gov.br/ccivil_03/_ato20072010/2010/lei/112305.htm>. Acesso em: 11 jun. 2021.

BRASIL. Resolução n. 2, de 15 de junho de 2012. Estabelece as Diretrizes Curriculares Nacionais para a Educação Ambiental. Brasília: MEC, 2012. Disponível em: <http://portal.mec.gov.br/dmdocuments/rcp002_12.pdf>. Acesso em: 11 jun. 2021.

BRASIL. Lei $n^{\circ}$ 9.605, de 12 de fevereiro de 1998 e Decreto $n^{\circ}$ 6.514, de 22 de julho de 2008. 2. ed., revista e atualizada. Brasília: IBAMA/CNIA, 2014a.

BRASIL. Política Nacional de Promoção da Saúde - PNPS: revisão da Portaria MS/ GM nº 687, de 30 de março de 2006. Brasília: MS, 2014b.

BRASIL. Diagnóstico do Manejo de Resíduos Sólidos Urbanos - 2016. Brasília: MCIDADES/SNSA, 2018.

CAMPINA GRANDE. Município. Plano Municipal de Gestão Integrada de Resíduos Sólidos do Município de Campina Grande - PB (PMGIRS)- Prognóstico, Diretrizes, Estratégias e Metas. Campina Grande: Prefeitura Municipal/Secretaria de Serviços Urbanos e Meio Ambiente - Sesuma, 2014.

CONFERÊNCIA INTERGOVERNAMENTAL SOBRE EDUCAÇÃO AMBIENTAL - Tbilisi, Geórgia, 14 a 26 de outubro de 1977. In.: SÃO PAULO (Estado). Coordenadoria de Educação 
Ambiental e Desenvolvimento: documentos oficiais / Secretaria de Meio Ambiente - São Paulo: A Secretaria, 1994, p. 27-53.

COSTA, C. A.; LOUREIRO, C. F. Interdisciplinaridade, Materialismo Histórico-Dialético e Paradigma da Complexidade: Articulações em Torno da Pesquisa em Educação Ambiental Crítica. Pesquisa em Educação Ambiental, Rio Claro, v.14, n.1, p. 32-47, 2019.

FRANCO, I.K. Valores e comportamento ecológico: uma análise comparativa e evolutiva dos alunos de dois cursos de graduação da USP, 2012. 108 f. Dissertação (Mestrado em Administração) Universidade de São Paulo, Ribeirão Preto, 2012.

GASKELL, G. Entrevistas individuais e grupais. In: BAUER, M. W.; GASKELL, G. (Orgs.) Pesquisa qualitativa com texto, imagem e som: um manual prático. 11 ed. Petrópolis: Vozes, 2013. p.64-89.

GUADAGNIN, M.R.; SELAU, C.C.; CADORIN, S.B. Gestão e gerenciamento de resíduos sólidos no município de Criciúma/SC. Revista Tecnologia e Ambiente, Criciúma, v. 24, p. 159-180, 2018. GLASER, B.; STRAUSS, A. The discovery of grounded theory: Strategies for qualitative research. New York: Aldine Publishing Company, 1967.

IBGE - Instituto Brasileiro de Geografia e Estatística - População estimada - 2020. Campina Grande PB: IBGE, 2020. Disponível em: https://www.ibge.gov.br/cidades-e-estados/pb/campina-grande.html. Acesso em: 08 ago. 2020.

ISWA - International Solid Waste Association. Annual Review - 2017. Viena: ISWA, 2018.

JACOBI, P. Educação ambiental, cidadania e sustentabilidade. Cadernos de Pesquisa, São Paulo, [s.v.], n.118, p. 189-205, mar. 2003.

LEFF, E. Complexidade, racionalidade ambiental e diálogo de saberes. Educação \& Realidade, Porto Alegre, v.34, n.3, p. 17-24, 2009.

LEFF, E. Saber Ambiental: Sustentabilidade, Racionalidade, Complexidade e Poder. 9 ed, Petrópolis: Vozes, 2012.

MATTOS, P.H.; ANELLO, L.F.S.; TAGLIANI, C.R.A. Uma análise sistêmica do gerenciamento dos resíduos sólidos em nove municípios da zona sul do Rio Grande do Sul. Diálogos \& Ciência, Salvador: Rede de Ensino FTC, v. 11, n. 33, p. 45-49, 2013.

doi: $10.7447 /$ dc. 2013.010

MAZZINI, A.L.D.A. Nosso lixo de cada dia: desafios e oportunidades. 2 ed. Belo Horizonte: Diretoria de Educação e Extensão Ambiental, 2012.

MINAYO, M.C.S. Amostragem e Saturação em Pesquisa Qualitativa: Consensos e Controvérsias. Revista Pesquisa Qualitativa, São Paulo, v. 5, n. 7, p. 01-12, abr. 2017.

MORAES, M.A.; THEIS, V.; VIER, M.B.; SCHREIBER, D. Análise dos Custos Ambientais Relacionados com a Gestão de Resíduos em Indústrias Químicas. RACE, Joaçaba, v. 16, n. 2, p. $505-$ 522, mai./ago. 2017.

MORIN, E. Introdução ao pensamento complexo - tradução Eliane Lisboa. 5.ed. - Porto Alegre: Sulina, 2015. 120 p.

MUCELIN, C.A.; BELLINI, M. Lixo e impactos ambientais perceptíveis no ecossistema urbano. Sociedade \& Natureza, Uberlândia, v.20, n.1, p.111-124, 2008. 
NEVES, L.M.; LUTINSKI, J.A.; TIBURSKI, J. Resíduos sólidos urbanos dispostos em terrenos baldios da cidade de Chapecó, SC. Revista Interdisciplinar de Estudos em Saúde, Caçador, v.7, n. 1, p.144-156, 2018.

OLIVEIRA, C.K.; SAHEB, D. RODRIGUES, D.G. A Educação Ambiental e a Prática Pedagógica: um diálogo necessário. Revista Educação, Santa Maria - RS, v. 45, [s.n.], p. 1-26, 2020.

ONU - Organização Das Nações Unidas - Transformando Nosso Mundo: a Agenda 2030 para o Desenvolvimento Sustentável. Nova Iorque: ONU, 2015.

PEREIRA, A.M.F. - Do global ao local: a Agenda 2030 da ONU e a gestão de resíduos sólidos no Brasil. 2018. 116 f. Dissertação (Mestrado em Relações Internacionais) - Universidade Federal da Bahia, Salvador, 2018.

PHILIPPI JÚNIOR, A.; AGUIAR, A.O. Resíduos sólidos: características e gerenciamento. In: PHILIPPI JÚNIOR, A. (editor). Saneamento, saúde e ambiente: fundamentos para um desenvolvimento sustentável. Barueri: Manole, 2005. p. 267-321.

PRÜSS-ÜSTÜN, A.; CORVALÁN, C. Preventing disease through healthy environments - Towards an estimate of the environmental burden of disease. Geneva: World Health Organization, 2006.

SORRENTINO, M. (Org.). Educação ambiental e políticas públicas: conceitos, fundamentos e vivências. 2 ed. Curitiba: Appris, 2018.

REVEILLEAU, A.C.A. Política Nacional de Resíduos Sólidos: aspectos da responsabilidade dos geradores na cadeia do ciclo de vida do produto. Revista Internacional de Direito e Cidadania, São Paulo, n.10, p.163-174, 2011.

SEABRA, G. (Org.). Educação Ambiental: conceitos e aplicações. João Pessoa: Editora da UFPB, 2013.

SILVA FILHO, C.R.V.; SOLER, F.D. Gestão de resíduos sólidos: o que diz a lei. São Paulo: Trevisan, 2012.

SILVA, M.M.P.; SOUSA, J.T.; CEBALLOS, B.S.O.; FEITOSA, W.B.S. e LEITE, V.D. Avaliação Sanitária de Resíduos Sólidos Orgânicos Domiciliares em Municípios do Semiárido Paraibano. Revista Caatinga, Mossoró, v. 23, n. 2, p. 87-92, 2010.

SOARES, F.A.A.; CARPILOVSKY, C.K.; COSTABEBER, I.H. Saúde e qualidade de vida do ser humano no contexto da interdisciplinaridade da Educação Ambiental. Revista Educação Ambiental em Ação, [revista eletrônica], v. X, n. 38, p. 01-06, Dez./2011/Fev./2012. Disponível em: http://www.revistaea.org/artigo.php?idartigo=1143. Acesso em: 18 jul. 2020.

SOUZA, A.P.B.; SOUZA, P.M. Resíduos Sólidos Urbanos Dispostos em Terrenos Baldios: problemas ambientais e de saúde. In.: SOUZA, P.M.; SOUZA, A.P.B.; COSTA, L.L. (Orgs.). Saúde ambiental: um olhar reflexivo. Campina Grande: EPGRAF, 2013. p. 204-224.

TESSARO, A.B.; SÁ, J.S.; SCREMIN, L.B. Quantificação e classificação dos resíduos procedentes da construção civil e demolição no município de Pelotas, RS. Ambiente Construído, Porto Alegre, v.12, n.2, p. 121-130, 2012.

UNCRD - United Nations Centre for Regional Development. Environment for sustainable development. Nagoya - Japan: UNCRD, Annual Reports 2017/2018. Disponível em: https://www.uncrd.or.jp/content/documents/377ARs2017-2018.pdf. Acesso em: 30 ago. 2020. 
UHMANN, R.I.M.; VORPAGEL, F.S. Educação Ambiental em Foco no Ensino Básico. Pesquisa em Educação Ambiental, Rio Claro, v.13, n.2, p. 53-68, 2018. Disponível em:

<http://dx.doi.org/10.18675/2177-580X.vol13.n2.p53-68>. Acesso em: 11 jun. 2021.

UNESCO - Taller subregional de educación ambiental para la enseñanza secundaria. Chosica, Perú, 1 a 19 de março de 1976, UNESCO: Ministerio de Educación del Perú.

YOSHIDA, C. Competência e as diretrizes da PNRS: conflitos e critérios de harmonização entre as demais legislações e normas. In: PHILIPPI Jr., A. (Coord). Política nacional, gestão e gerenciamento de resíduos sólidos. São Paulo: Manole, 2012. p.3-38. 